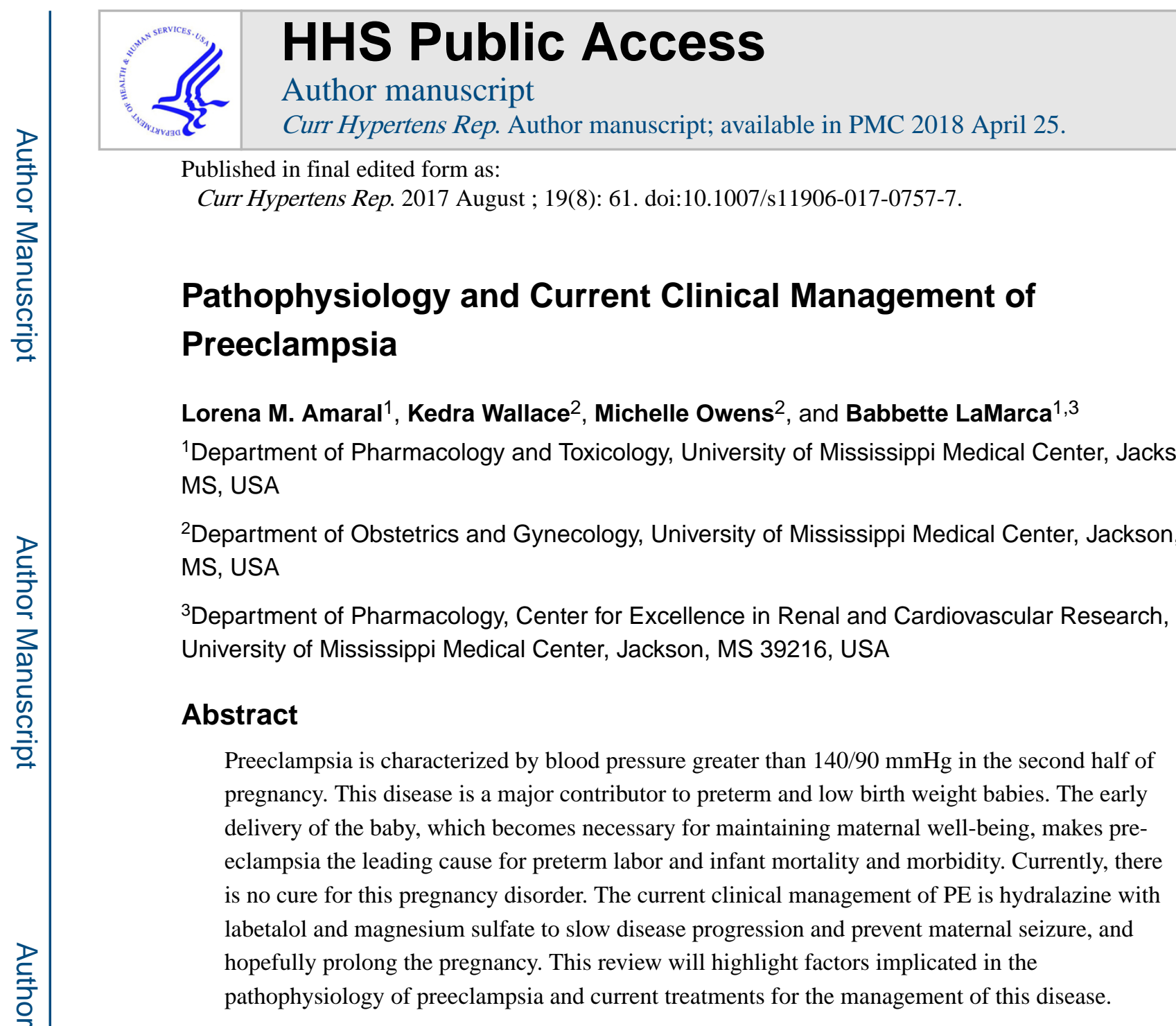

Keywords

Preeclampsia; Placental ischemia; Inflammation; Endothelial dysfunction

\title{
Introduction
}

Preeclampsia (PE) is a pregnancy specific multisystem hypertensive disorder that is a major contributor to maternal, neonatal morbidity and mortality. PE is responsible for an estimated $50,000-60,000$ pregnancy-related deaths per year worldwide $[1 \bullet \cdot, 2-6]$. This disease is associated with new-onset hypertension in the second half of pregnancy and is often associated with proteinuria. Complications such as eclampsia, hemorrhagic stroke, hemolysis, elevated liver enzymes and low platelets (HELLP syndrome), renal failure and pulmonary edema may be associated with PE.

Correspondence to: Babbette LaMarca.

Compliance with Ethical Standards

Conflict of Interest The authors declare no conflicts of interest relevant to this manuscript.

Human and Animal Rights and Informed Consent This article does not contain any studies with human or animal subjects performed by any of the authors. 
Although the underlying pathophysiology of PE is not completely understood, hallmark characteristics of this disease include increased uterine artery resistance index (UARI), chronic immune activation, intrauterine fetal growth restriction (IUGR), increased inflammatory cytokines, maternal endothelial dysfunction, decreased vasodilators, and other systemic disturbances (Fig. 1) [7-14]. Importantly, the only resolve for PE is delivery of placenta, leaving this disease one of the leading causes of preterm birth.

\section{Pathophysiology of Preeclampsia}

The inappropriate vascular remodeling and a hypoperfused placenta, which result from the shallow cytotrophoblast migration toward the uterine spiral arterioles, have been characterized as an important initiating events in PE [15•]. The placenta becomes ischemic which leads to the release of factors that are associated with maternal vascular endothelial dysfunction [11, 12, 15•, 16-18]. Endothelial dysfunction has been a common phenotype of $\mathrm{PE}$ and it is characterized by vasoconstriction and reduced blood flow to organs. Furthermore, preexisting conditions such as diabetes and obesity contribute to factors released from the ischemic placenta. In addition, an increase in immune cells and inflammatory cytokines are related to endothelial dysfunction during PE [9, 19-21]. Importantly, hallmarks such as endothelin-1 (ET-1), anti-angiogenic factor sFlt-1, agonistic autoantibodies to the angiotensin II type I receptor (AT1-AA) and decreased nitric oxide (NO) have been shown to play an important role in the development of PE [22-26, 27••].

\section{Endothelial Dysfunction Is a Common Thread that Could Contribute to Pathology of PE}

During PE, the mechanisms responsible for systemic maternal vascular dysfunction are still not fully understood. However, anti-angiogenic factors such as sFlt-1 or soluble vascular endothelial growth factor receptor 1 have been associated with decreased renal function and hypertension during pregnancy. Circulating sFlt-1 levels and placental sFlt-1 mRNA are higher in women who have preeclampsia compared to normal pregnant women [25]. Also, animal data have demonstrated that sFlt-1 induces PE-like syndrome, which was associated with increased ET-1 and decreased NO and resulting in endothelial dysfunction [23•]. Previous studies have demonstrated that ET-1 is increased in PE and some studies report a positive correlation between ET-1 and the severity of symptoms. NO is required vascular alterations during normal pregnancy to support the increased blood volume [28]. NO deficiency has been shown to impair the vasorelaxation in human and animal models of PE [29-31] and increased NO bioavailability could contribute to improve maternal and fetal outcomes.

\section{Chronic Inflammation Contributes to Endothelial Dysfunction and to the Pathology of PE}

During a normal pregnancy, there is a careful balance between TH1 and TH2 immune cells and their respective immune responses. However in PE, this balance is disrupted and there is a shift toward a TH1 response leading to a chronic immune environment similar to that 
experienced by individuals with autoimmune diseases [19, 20, 32]. The increase in TH1 immune cells and cytokines increases the B cell production of autoantibodies to the angiotensin II (Ang II) type 1 receptor (AT1-AA) [26, 27•, 33], increases ET-1 and sFlt-1 expression [34, 35] and increases oxidative stress [36-38], all of which contribute to the pathophysiology of PE and ultimately the development of hypertension during pregnancy.

What is becoming more apparent is that despite the unknown etiology of PE, women with obesity or a high body mass index (BMI: $>30 \mathrm{~kg} / \mathrm{m}^{2}$ ) [39, 40], chronic hypertension, diabetes and systemic lupus erythematosus (SLE) prior to pregnancy are more susceptible to the development of PE [41, 42]. As obesity represents a chronic state of low-grade inflammation, is a risk factor for PE [39, 43, 44]. In addition to the systemic inflammation that is associated with obesity, a study by Aye et al. [45] has shown that as body mass index increases so does placental activation of inflammatory pathways. Placentas from obese women have also been shown to be lipotoxic and have increased oxidative stress [46, 47].

Women with chronic hypertension who develop PE, superimposed-PE (SI-PE), have a different immune profile compared to PE women [48]. Though women with chronic hypertension and SI-PE have evidence of chronic inflammation, the ratio of sFlt-1/PlGF does not reach the levels of severity as they do in women with just PE. The sFlt-1/PlGF ratio in late pregnancy is not as severe as that experienced by women with PE suggesting that the inflammatory pathway triggered in PE might be different compared to that of hypertension alone since an additive effect has not been reported.

Women with type 1 diabetes (T1D), type 2 diabetes (T2D) or gestational diabetes (GD) are all at an increased risk of developing PE. Approximately 15-20\% of pregnant women with T1D [49-51], 10-14\% of pregnant women with T2D [51, 52] will develop PE and women with GD have an odds ratio $=1.3$ (95\% confidence interval 1.2, 1.4) of developing PE [53]. Both T1D and T2D are associated with chronic low-grade inflammation [54], which along with the fact that women with PE tend to be insulin resistant prior to pregnancy could stand as one reason why women with diabetes are more susceptible to PE [55]. Women with GD have an immune profile similar to that of women with PE, as there is evidence of endothelial dysfunction [56], angiogenic imbalance [57] and an increase in oxidative stress [58]. As PE is associated with insulin resistance as well as immune dysregulation, it is less clear as to whether there is a common etiological pathway between GD and PE.

SLE is an autoimmune disease that predominantly affects women in their childbearing years and is associated with immune alteration, specifically a reduction in Treg cells. Over $20 \%$ of pregnant women with SLE have pregnancies complicated with PE [59, 60]. For women with lupus nephritis, kidney inflammation due to SLE, who become pregnant, the decrease in Tregs, which are needed for a successful pregnancy puts them at an increased risk for PE [61-64]. SLE is also associated with antiphospholipid antibodies (aPLs) which is associated with PE, preterm birth and intrauterine growth restriction (IUGR) [65, 66]. As all of these abovementioned disorders have an underlying theme of chronic inflammation, it can be suggested that when a pathological inflammatory insult is superimposed onto the proinflammatory state of pregnancy, more severe complications of pregnancy, such as PE may develop [21]. 


\section{Preeclampsia Affects Not Only the Mother but Also the Offspring}

As delivery of the placenta is the only effective treatment for PE, babies born to women with $\mathrm{PE}$ often suffer from intrauterine growth restriction and preterm birth along with some of the associated neonatal comorbidities (i.e., respiratory distress syndrome, intraventricular hemorrhage) and increased fetal pro-inflammatory profiles [67•]. In addition to this, these children are more susceptible to neurodevelopmental and behavioral problems as well as cardiovascular diseases as they age [68•]. All of which suggest that we still need to further our understanding of the complex relationship between the ischemic placenta, maternal inflammation and fetal programming.

\section{Clinical Management of PE}

The focus of clinical management of preeclampsia are prevention of maternal morbidity by aggressive treatment of hypertensive emergency, maternal seizure prevention in severe preeclampsia, and limiting injury to the fetus. These three principles are carried out through the administration of medications and with the application of fetal surveillance to assess fetal status. If treatment fails to correct severe maternal hypertension or if there is evidence of non-reassuring fetal status, delivery is warranted.

Recognition and management of persistently elevated (greater than 15 min in duration)

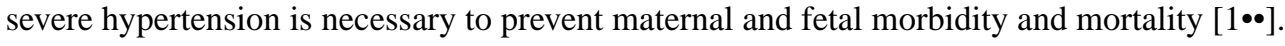
This is accomplished through aggressive treatment of SBP $\geq 160 \mathrm{mmHg}$ and/or DBP $\geq 105$ mmHg. Labetalol (a beta-blocker) and/or hydralazine (a vasodilator) are considered first-line therapy for acute hypertensive emergency and are administered intravenously as a bolus. Immediate-release oral nifedipine, a calcium channel blocker, may also be used as first-line therapy, especially when intravenous access is not available [69]. The goal of treatment is to lower maternal blood pressure $15-25 \%$, with a goal SBP of $140-150 \mathrm{mmHg}$ and DBP of 90-100 $\mathrm{mmHg}$ (Fig. 2). Care is taken to avoid excessive lowering of blood pressure, as this may further decrease placental perfusion and potentiate negative effects on fetal status. When severe PE develops prior to 34 weeks gestation in the otherwise stable patient, conservative inpatient management may be considered. In the event of progressive severe disease or HELLP syndrome, delivery is indicated. Plasma exchange and steroid therapy have also been used in the care of women with recalcitrant severe preeclampsia and unremitting HELLP syndrome with favorable results [70••].

Prophylaxis against maternal seizures (eclampsia) is achieved by the use of magnesium sulfate [63]. Magnesium sulfate is administered either as an intravenous bolus or intramuscular injection. While magnesium sulfate may have the favorable effect of lowering maternal blood pressure, it has been shown to be superior to other anticonvulsants in the prevention of eclamptic seizures and is considered first-line therapy. However, when magnesium sulfate is either contraindicated or unavailable, traditional anticonvulsants may be used.

Fetal assessment is determined based on gestational age and maternal status. In more acute settings, continuous fetal monitoring is used in an effort to assess for signs of intrauterine 
hypoxia. After maternal stabilization, other mechanisms of fetal assessment (biophysical profiles, fetal non-stress tests, fetal umbilical artery Doppler assessments) may be used. If fetal assessments are non-reassuring, delivery is warranted.

\section{Conclusion}

Preeclampsia is a multisystem disorder which is characterized by hypertension and endorgan dysfunction. It is a source of significant maternal and fetal morbidity and mortality worldwide. While our understanding of the pathophysiology of pre-eclampsia has grown significantly in the past decades, greater understanding of the complex relationship between placental ischemia, maternal inflammation, and fetal programming is needed.

The only known cure for preeclampsia is delivery of the placenta, which often results in premature delivery of the fetus, exposing the newborn to the immediate risks of prematurity as well as additional risks for metabolic disturbances and chronic diseases across the lifespan of the child. Preeclampsia has also been shown to increase the risk for cardiovascular disease and overall mortality in those women affected by the disease.

Aggressive management of persistent severe maternal hypertension, seizure prophylaxis with magnesium sulfate, and assessment of fetal well-being are the hallmarks of clinical management. When administered timely and appropriately, these interventions have been shown to decrease maternal and fetal morbidity and mortality [71].

\section{Acknowledgments}

This work was funded by the NIH grants HL105324 and HD067541-06.

\section{References}

Papers of particular interest, published recently, have been highlighted as:

- Of importance

•- Of major importance

1•. American College of O Gynecologists, Task Force on Hypertension in P. Hypertension in pregnancy. Report of the American College of Obstetricians and Gynecologists' Task Force on Hypertension in Pregnancy. Obstetrics and gynecology. 2013; 122(5):1122-31. This report highlights recommendations and guidelines for the management of patients with hypertension during and after pregnancy. DOI: 10.1097/01.AOG.0000437382.03963.88 [PubMed: 24150027]

2. Creasy, RK., Resnik, R., Greene, MF., Iams, JD., Lockwood, CJ. Creasy and Resnik's maternal-fetal medicine: principles and practice. 7.

3. Duley L. Maternal mortality associated with hypertensive disorders of pregnancy in Africa, Asia, Latin America and the Caribbean. Br J Obstet Gynaecol. 1992; 99(7):547-53. [PubMed: 1525093]

4. Wallukat G, Homuth V, Fischer T, Lindschau C, Horstkamp B, Jupner A, et al. Patients with preeclampsia develop agonistic auto-antibodies against the angiotensin AT1 receptor. J Clin Investig. 1999; 103:945-52. [PubMed: 10194466]

5. Duley L. The global impact of pre-eclampsia and eclampsia. Semin Perinatol. 2009; 33(3):130-7. DOI: 10.1053/j.semperi.2009.02.010 [PubMed: 19464502] 
6. Khan KS, Wojdyla D, Say L, Gulmezoglu AM, Van Look PF. WHO analysis of causes of maternal death: a systematic review. Lancet. 2006; 367(9516):1066-74. DOI: 10.1016/ S0140-6736(06)68397-9 [PubMed: 16581405]

7. Conrad KP, Benyo DF. Placental cytokines and the pathogenesis of preeclampsia. Am J Reprod Immunol. 1997; 37(3):240-9. [PubMed: 9127646]

8. Gilbert JS, Ryan MJ, LaMarca BB, Sedeek M, Murphy SR, Granger JP. Pathophysiology of hypertension during preeclampsia: linking placental ischemia with endothelial dysfunction. Am J Physiol Heart Circ Physiol. 2008; 294(2):H541-50. DOI: 10.1152/ajpheart.01113.2007 [PubMed: 18055511]

9. Lamarca B. The role of immune activation in contributing to vascular dysfunction and the pathophysiology of hypertension during preeclampsia. Minerva Ginecol. 2010; 62(2):105-20. [PubMed: 20502423]

10. Matsubara K, Matsubara Y, Hyodo S, Katayama T, Ito M. Role of nitric oxide and reactive oxygen species in the pathogenesis of preeclampsia. J Obstet Gynaecol Res. 2010; 36(2):239-47. DOI: 10.1111/j.1447-0756.2009.01128.x [PubMed: 20492372]

11. Noris M, Perico N, Remuzzi G. Mechanisms of disease: pre-eclampsia. Nat Clin Pract Nephrol. 2005; 1(2):98-114. quiz 20. DOI: 10.1038/ncpneph0035 [PubMed: 16932375]

12. Redman CW, Sargent IL. Latest advances in understanding pre-eclampsia. Science. 2005; 308(5728):1592-4. DOI: 10.1126/science.1111726 [PubMed: 15947178]

13. Sandrim VC, Montenegro MF, Palei AC, Metzger IF, Sertorio JT, Cavalli RC, et al. Increased circulating cell-free hemoglobin levels reduce nitric oxide bioavailability in preeclampsia. Free Radic Biol Med. 2010; 49(3):493-500. DOI: 10.1016/j.freeradbiomed.2010.05.012 [PubMed: 20510352]

14. Amaral LM, Palei AC, Sandrim VC, Luizon MR, Cavalli RC, Duarte G, et al. Maternal iNOS genetic polymorphisms and hypertensive disorders of pregnancy. J Hum Hypertens. 2012; 26(9): 547-52. DOI: 10.1038/jhh.2011.65 [PubMed: 21716319]

15•. Roberts JM, Gammill HS. Preeclampsia: recent insights. Hypertension. 2005; 46(6):1243-9. The review highlights valuable insights into pathophysiology that could guide ongoing clinical trials. DOI: 10.1161/01.HYP.0000188408.49896.c5 [PubMed: 16230510]

16. Granger JP. Inflammatory cytokines, vascular function, and hypertension. American journal of physiology Regulatory, integrative and comparative physiology. 2004; 286(6):R989-90. DOI: 10.1152/ajpregu.00157.2004

17. Granger JP, Alexander BT, Llinas MT, Bennett WA, Khalil RA. Pathophysiology of preeclampsia: linking placental ischemia/ hypoxia with microvascular dysfunction. Microcirculation. 2002; 9(3): 147-60. DOI: 10.1038/sj.mn.7800137 [PubMed: 12080413]

18. Sankaralingam S, Arenas IA, Lalu MM, Davidge ST. Preeclampsia: current understanding of the molecular basis of vascular dysfunction. Expert Rev Mol Med. 2006; 8(3):1-20. DOI: 10.1017/ S1462399406010465

19. Redman CW, Sargent IL. Immunology of pre-eclampsia. Am J Reprod Immunol. 2010; 63(6):53443. DOI: 10.1111/j.1600-0897.2010.00831.x [PubMed: 20331588]

20. Lamarca B, Cornelius D, Wallace K. Elucidating immune mechanisms causing hypertension during pregnancy. Physiology. 2013; 28:225-33. [PubMed: 23817797]

21. Borzychowski A, Sargent I, Redman C. Inflammation and pre-eclampsia. Semin Fetal Neonatal Med. 2006; 11(5):309-16. [PubMed: 16828580]

22. LaMarca BD, Ryan MJ, Gilbert JS, Murphy SR, Granger JP. Inflammatory cytokines in the pathophysiology of hypertension during preeclampsia. Curr Hypertens Rep. 2007; 9(6):480-5. [PubMed: 18367011]

23•. Murphy SR, LaMarca BB, Cockrell K, Granger JP. Role of endothelin in mediating soluble fmslike tyrosine kinase 1-induced hypertension in pregnant rats. Hypertension. 2010; 55(2):394-8.

The study shows the important role of sFlt-1 to induce PE-like syndrome through nitric oxide and endothelin-1 pathways. DOI: 10.1161/HYPERTENSIONAHA.109.141473 [PubMed: 20026766]

24. Murphy SR, LaMarca BB, Parrish M, Cockrell K, Granger JP. Control of soluble fms-like tyrosine-1 (sFlt-1) production response to placental ischemia/hypoxia: role of tumor necrosis 
factor-alpha. American journal of physiology Regulatory, integrative and comparative physiology. 2013; 304(2):R130-5. DOI: 10.1152/ajpregu.00069.2012

25. Maynard SE, Min JY, Merchan J, Lim KH, Li J, Mondal S, et al. Excess placental soluble fms-like tyrosine kinase 1 (sFlt1) may contribute to endothelial dysfunction, hypertension, and proteinuria in preeclampsia. J Clin Invest. 2003; 111(5):649-58. DOI: 10.1172/JCI17189 [PubMed: 12618519]

26. Dechend R, Muller D, Wallukat G, Homuth V, Krause M, Dudenhausen J, et al. AT1 receptor agonistic antibodies, hypertension, and preeclampsia. Semin Nephrol. 2004; 24(6):571-9. [PubMed: 15529292]

27••. LaMarca B, Wallace K, Granger J. Role of angiotensin II type I receptor agonistic autoantibodies (AT1-AA) in preeclampsia. Current Opinions in Pharmacology. 2011; 11(2):175-9. This review discusses the potential role of the AT1-AA in mediating hypertension during pregnancy.

28. Noris M, Todeschini M, Cassis P, Pasta F, Cappellini A, Bonazzola S, et al. L-arginine depletion in preeclampsia orients nitric oxide synthase toward oxidant species. Hypertension. 2004; 43(3):61422. DOI: 10.1161/01.HYP.0000116220.39793.c9 [PubMed: 14744923]

29. Eleuterio NM, Palei AC, Rangel Machado JS, Tanus-Santos JE, Cavalli RC, Sandrim VC. Relationship between adiponectin and nitrite in healthy and preeclampsia pregnancies. Clinica chimica acta; international journal of clinical chemistry. 2013; 423:112-5. DOI: 10.1016/j.cca. 2013.04.027 [PubMed: 23643962]

30. Sandrim VC, Palei AC, Metzger IF, Cavalli RC, Duarte G, Tanus-Santos JE. Interethnic differences in ADMA concentrations and negative association with nitric oxide formation in preeclampsia. Clinica chimica acta; international journal of clinical chemistry. 2010; 411(19-20):1457-60. DOI: 10.1016/j.cca.2010.05.039 [PubMed: 20570587]

31. Murphy SR, LaMarca B, Cockrell K, Arany M, Granger JP. L-arginine supplementation abolishes the blood pressure and endothelin response to chronic increases in plasma sFlt-1 in pregnant rats. American journal of physiology Regulatory, integrative and comparative physiology. 2012; 302(2):R259-63. DOI: 10.1152/ajpregu.00319.2011

32. Perez-Sepulveda A, Torres M, Khoury M, Illanes S. Innate immune system and preeclampsia. Front Immunol. 2014; 5:244. [PubMed: 24904591]

33. Dhillion P, Wallace K, Scott J, Herse F, Heath J, Moseley J, et al. IL-17 mediated oxidative stress is an important stimulator of AT1-AA and hypertension during pregnancy. Am J Physiol Regul Integr Comp Physiol. 2012; 303(4):R353-R8. [PubMed: 22718806]

34. LaMarca B, Alexander B, Gilbert J, Ryan M, Sedeek M, Murphy S, et al. Pathophysiology of hypertension in response to placental ischemia during pregnancy: a central role for endothelin? Gender Medicine. 2008; 5:S133-S8. [PubMed: 18395679]

35. Wallace K, Novotny S, Heath J, Moseley J, Martin J, Owens M, et al. Hypertension in response to $\mathrm{CD} 4+\mathrm{T}$ cells from reduced uterine perfusion pregnant rats is associated with activation of the endothelin-1 system. Am J Physiol Regul Integr Comp Physiol. 2012; 303(2):R144-9. [PubMed: 22647295]

36. Raijmakers M, Dechend R, Poston L. Oxidative stress and pre-eclampsia: rationale for antioxidant clinical trials. Hypertension. 2004; 44:374-80. [PubMed: 15326082]

37. Redman C, Sargent I. Placental debris, oxidative stress and pre-eclampsia. Placenta. 2000; 21(7): 597-602. [PubMed: 10985960]

38. Wallace K, Cornelius D, Scott J, Heath J, Moseley J, Chatman K, et al. CD4 ${ }^{+}$T cells are important mediators of oxidative stress that cause hypertension in response to placental ischemia. Hypertension. 2014; 64(5):1151-8. DOI: 10.1161/HYPERTENSIONAHA.114.03590 [PubMed: 25259742]

39. Walsh S. Obesity: a risk factor for preeclampsia. Trends in Endocrinology \& Metabolism. 2007; 18(10):365-70. [PubMed: 18023357]

40. Spradley F, Palei A, Granger J. Increased risk for the development of preeclampsia in obese pregnancies: weighing in on the mechanisms. Am J Physiol Regul Integr Comp Physiol. 2015; 309(11):R1326-43. [PubMed: 26447211] 
41. Villa P, Marttinen P, Gillberg J, Lokki A, Majander K, Orden M, et al. Cluster analysis to estimate the risk of preeclampsia in the high-risk prediction and prevention of preeclampsia and intrauterine growth restriction (PREDO) study. PLoS One. 2017; 12(3):e0174399. [PubMed: 28350823]

42. Bartsch E, Medcalf K, Park A, Ray J. Group HRoP-eI. Clinical risk factors for pre-eclampsia determined in early pregnancy: systematic review and meta-analysis of large cohort studies. BMJ. 2016; 353:i1753. [PubMed: 27094586]

43. Spradley F, Palei A, Granger J. Immune mechanisms linking obesity and preeclampsia. Biomol Ther. 2015; 5:3142-76.

44. Womack J, Tien P, Feldman J, Shin J, Fennie K, Anastos K, et al. Obesity and immune cell counts in women. Metabolism. 2007; 56(7):998-1004. [PubMed: 17570264]

45. Aye I, Lager S, Ramirez V, Gaccioli F, Dudley D, Jasson T, et al. Increasing maternal body mass index is associated with systemic inflammation in the mother and the activation of distinct placental inflammatory pathways. Biol Reprod. 2014; 90(6):129. [PubMed: 24759787]

46. Zavalza-Gomez A. Obesity and oxidative stress: a direct link to preeclampsia? Arch Gyneccol Obstet. 2011; 283(3):415-22.

47. Saben J, Lindsey F, Zhong Y, Thakali K, Badger T, Andres A, et al. Maternal obesity is associated with a lipotoxic placental environment. Placenta. 2014; 35:171-7. [PubMed: 24484739]

48. Costa R, Hoshida M, Alves E, Zugaib M, Francisco R. Preeclampsia and superimposed preeclampsia: the same disease? The role of angiogenic biomarkers. Hypertension in Pregnancy. 2016; 35(2):139-49. [PubMed: 26930132]

49. Jensen D, Damm P, Moelsted-Pedersen L, Ovesen P, Westergaard J, Moeller M, et al. Outcomes in type 1 diabetic pregnancies: a nationwide, population-based study. Diabetes Care. 2004; 27(12): 2819-23. [PubMed: 15562191]

50. Persson M, Norman M, Hanson U. Obstetric and perinatal outcomes in type 1 diabetic pregnancies: a large, population-based study. Diabetes Care. 2009; 32(11):2005-9. [PubMed: 19675195]

51. Knight K, Thornburg L, Pressman E. Pregnancy outcomes in type 2 diabetic patients as compared with type 1 diabetic patients and nondiabetic controls. J Reprod Med. 2012; 57(9-10):397-404. [PubMed: 23091986]

52. Groen B, Links T, van den Berg P, Hellinga M, Moerman S, Visser G, et al. Similar adverse pregnancy outcome in native and nonnative Dutch women with pregestational type 2 diabetes: a multicentre retrospective study. ISRN Obstet Gynecol. 2013; 2013:361435. [PubMed: 24294525]

53. Weissgerber T, Mudd L. Preeclampsia and diabetes. Curr Diab Rep. 2015; 15(3):579.

54. Nunemaker C. Considerations for defining cytokine dose, duration and milieu that are appropriate for modeling chronic low-grade inflammation in type 2 diabetes. J Diabetes Res. 2016; 2016:2846570. [PubMed: 27843953]

55. Scioscia M, Gumaa K, Rademacher T. The link between insulin resistance and preeclampsia: new perspective. J Reprod Immunol. 2009; 82(2):100-5. [PubMed: 19628283]

56. Guimaraes M, Brandao A, Rezende C, Cabral A, Brum A, Leite H, et al. Assessment of endothelial function in pregnant women with pre-eclampsia and gestational diabetes mellitus by flowmediated dilation of brachial artery. Arch Gyneccol Obstet. 2014; 290(3):441-7.

57. Conti E, Zezza L, Ralli E, Caserta D, Musumeci M, Moscarini M, et al. Growth factors in preeclampsia: a vascular disease model. A failed vasodilation and angiogenic challenge from pregnancy onwards? Cytokine Growth Factor Rev. 2013; 24(5):411-25. [PubMed: 23800655]

58. Karacay O, Sepici-Dincel A, Karcaaltincaba D, Sahin D, Yalvac S, Akyol M, et al. A quantitative evaluation of total antioxidant status and oxidative stress markers in preeclampsia and gestational diabetic patients in 24-36 weeks gestation. Diabetes Res Clin Pract. 2010; 89(3):231-8. [PubMed: 20537747]

59. Clowse M, Jamison M, Myers E, James A. National study of medical complications in SLE pregnancies. Arthritis Rheum. 2006; 54(S9):S263.

60. Clark C, Spitzer K, Nadler J, Laskin C. Preterm deliveries in women with systemic lupus erythematosus. J Rheumatol. 2003; 30(10):2127-32. [PubMed: 14528505] 
61. Emerudh J, Berg G, Mjosberg J. Regulatory T helper cells in pregnancy and their roles in systemic versus local immune tolerance. Am J Reprod Immunol. 2011; 66(Suppl 1):31-43. [PubMed: 21726336]

62. Cornelius D, Amaral L, Harmon A, Wallace K, Thomas A, Campbell N, et al. An increased population of regulatory $\mathrm{T}$ cells improves the pathophysiology of placental ischemia in a rat model of preeclampsia. Am J Physiol Regul Integr Comp Physiol. 2015; 309(8):R884-R91. [PubMed: 26290102]

63. Prins J, Boelens H, Heimweg J, Van der Heide S, Dubois A, Van Oosterhout A, et al. Preeclampsia is associated with lower percentages of regulatory $\mathrm{T}$ cells in maternal blood. Hypertension in Pregnancy. 2009; 28:300-11. [PubMed: 19412837]

64. Gluhovschi C, Gluhovschi G, Petrica L, Velciov S, Gluhovschi A. Pregnancy associated with systemic lupus wrythematosus: immune tolerance in pregnancy and its deficiency in systemic lupus erythematosus — an immunological dilemma. J Immunol Res. 2015; 2015(241547)

65. Ulcova-Gallova Z, Mockova A, Cedikova M. Screening tests of reproductive immunology in systemic lupus erythematosus. Autoimmune Diseases. 2012; 2012:812138. [PubMed: 23150811]

66 . Hayslett J. The effect of systemic lupus erythematosus on pregnancy and pregnancy outcome. Am J Reprod Immunol. 1992; 28(3-4):199-204. [PubMed: 1285878]

67•. Guillemette L, Lacroix M, Allard C, Patenaude J, Battista M, Doyon M, et al. Preeclampsia is associated with an increased pro-inflammatory profile in newborns. J Reprod Immunol. 2015; 112:111-4. The study shows that newborns from mothers diagnosed with PE have higher levels of TNFa at birth. [PubMed: 26454417]

68• Nomura Y, John R, Janssen A, Davey C, Finik J, Buthmann J, et al. Neurodevelopmental consequences in offspring of mothers with preeclampsia during pregnancy: underlying biological mechanism via imprinting genes. Arch Gyneccol Obstet. 2017; 295(6):1319-29. This recent review attempts to show new evidence for imprinting gene dysregulation caused by hypertension and that could explain the link between preeclampsia and neurocognitive problems in offspring.

69. Too GT, Hill JB. Hypertensive crisis during pregnancy and post-partum period. Semin Perinatol. 2013; 37(4):280-7. DOI: 10.1053/j.semperi.2013.04.007 [PubMed: 23916027]

70••. Owens MY, Martin JN Jr, Wallace K, Keiser SD, Parrish MR, Tam Tam KB, et al. Postpartum thrombotic microangiopathic syndrome. Transfusion and apheresis science: official journal of the World Apheresis Association: official journal of the European Society for Haemapheresis. 2013; 48(1):51-7. This study reports an important patient case and discusses about the early recognition of thrombotic thrombocytopenic purpura for the appropriate treatment. DOI: $10.1016 / \mathrm{j}$.transci. 2012.05.016

71. Committee on Obstetric P. Committee Opinion No. 623: Emergent therapy for acute-onset, severe hypertension during pregnancy and the postpartum period. Obstet Gynecol. 2015; 125(2):521-525. DOI: 10.1097/01.AOG.0000460762.59152.d7 [PubMed: 25611642] 


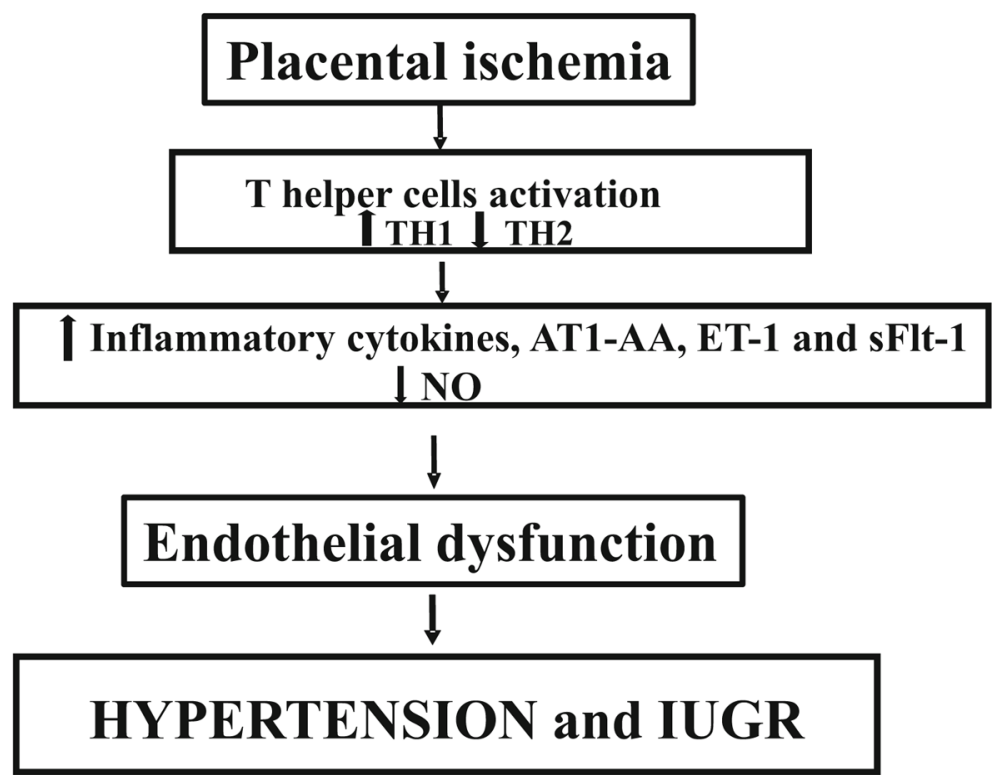

Fig. 1.

Placental ischemia leads to release of factors that play a role to pathophysiology of preeclampsia. Abbreviations: TH1 T helper cells type 1, TH2 T helper cells type 2, AT1-AA autoantibodies to angiotensin II type 1 receptor, ET-1 endothelin 1, sFlt-1 soluble vascular endothelial growth factor receptor $1, N O$ nitric oxide, $I U G R$ uterine growth restriction 


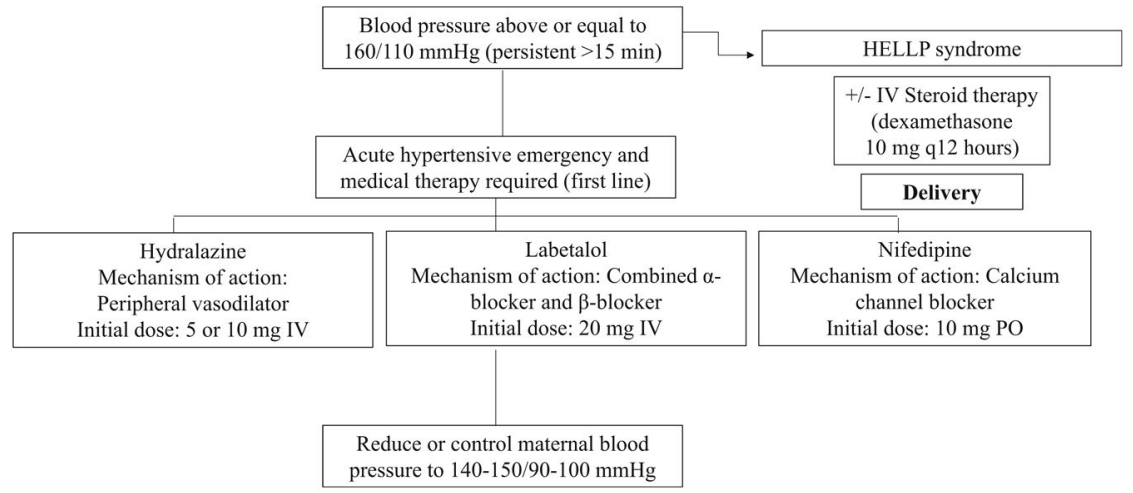

Fig. 2.

Management of onset hypertension in pregnancy. Abbreviations: PE preeclampsia, HELLP hemolysis, elevated liver enzymes, and low platelet count, $I V$ intravenous, $P O$ orally 